\title{
Methodologies for Dividing Profit in Networked Production Structures
}

\author{
Hendrik Jähn and Joachim Käschel \\ Chemnitz University of Technology, \\ Department of Economic Sciences, Professorship BWL VII \\ 09107 Chemnitz, Germany \\ hendrik.jaehn@wirtschaft.tu-chemnitz.de, \\ WWW home page: http://www.tu-chemnitz.de/wirtschaft/bwl7/
}

\begin{abstract}
This conceptual paper focuses the problem of dividing the profit earned in a production network to the different network members. In this context different theoretical approaches for profit division are introduced and discussed. It is assumed that a high degree of automation is aimed at by using the modern information and communication technology (ICT) intensively. The task of profit division is integrated in a comprehensive approach considering incentive and sanction mechanisms for harmonising the interests of the network members as well. In that context the basic assumptions of the New Institutional Economics serve as a theoretic basis.
\end{abstract}

\section{Keywords}

Production Network, Network Controlling, Profit Division

\section{Introduction}

The production of goods within networked organisation structures especially allows small and medium-sized enterprises (SME) to enter new markets. For the operation and coordination of production networks the management concept "Extended Value Chain Management" (EVCM) [1] was developed. This approach operates by automation at a high degree. It consists of nine phases representing the typical phases of a life-cycle of a production network.

For the modelling of the approaches of profit division the methodology of linear optimisation served as a base. Furthermore the microeconomic approach of the New Institutional Economics [2] with its basic assumptions limited rationality, 
opportunistic behaviour of actors and individual maximisation of utility in connection with asymmetrically distributed information among the economic actors is considered. For the solution of the problem the Principal-Agent-Theory serves as a valuable basis. Hereby the EVCM which represents the network can be interpreted as Principal while the network participants are the Agents. By using instruments for harmonising the interests of both actor groups the utility can be maximised. Options in that context are the introduction of incentive or sanction mechanisms [3] as specific modules of a comprehensive model for profit division. That approach is illustrated in fig. 1 .

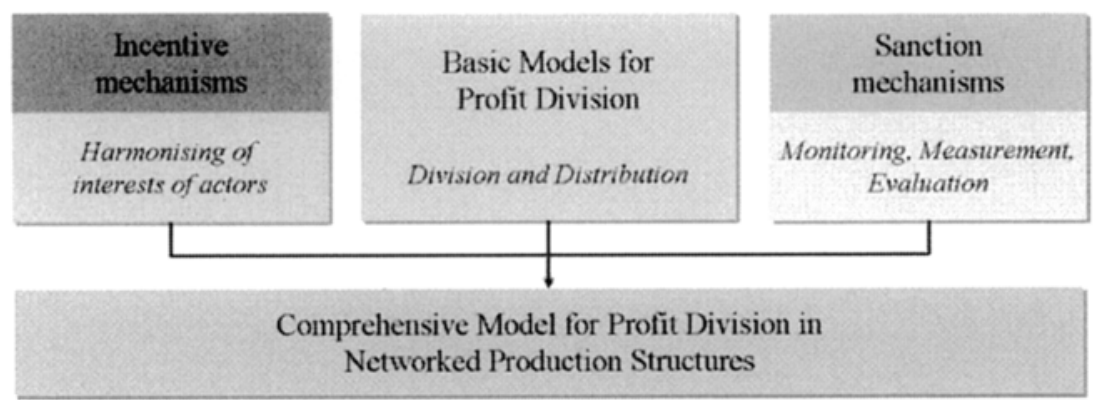

Fig. 1. Comprehensive Approach for profit division in networked production structures

It is obvious that there must be flexible but harmonised interfaces between the partial models. That is realised by the calculation of specific measures which allow a transfer of information.

\section{The Comprehensive Model}

\subsection{Basic Models for Profit Division}

In existent literature hardly any comprehensive models focusing that topic can be identified. As an exception a few game-theoretic approaches $[4,5]$, macroeconomic approaches [6] or approaches requiring a special framework $[7,8]$ can be identified. However these approaches are highly theoretic and applicable for real-world networks only to a very limited degree what marks the initial point for the development of specific approaches for SME-based production networks.

All profit division models described within this contribution consider three influencing parameters: a fixed share to cover the fixed costs, an added valuedependent share and a profit expectation dependent share. The least mentioned parameter represents the most important variable influencing the ascertainment of the individual profit shares of the single enterprises. Thereby, the individual profit expectation belongs to the input parameters of the model which are assumed and already introduced. 
Due to the consideration of the three components, some possibilities of variation occur for the further modelling. Such variations above all refer to the question whether the offer price or offer profit correspond to the sales price or profit or not. Thus, there are several possibilities of component integration for calculating profit shares under consideration of the three components. For example, the profit shares could first of all be calculated via the profit expectation and if a profit share remains, it can be divided under consideration of further components. A further opportunity is the introduction of weightings for each of those three components.

In principle, the calculation of the network profit which is included in the offer is based on the individual profit expectations of the enterprises. However, it is also imaginable that the profit expectation-dependent profit share paid out after the value adding process has been carried through, does not correspond to the total profit amount that can be divided. That so-called non-divided remaining profit is negative if a too high amount has been divided and it has a positive value if a profit share that has to be divided remains. In both cases, measures have to be taken in order to divide the earned profit exactly. Therefore, we suggest either a corresponding revaluation or devaluation by using a standardisation parameter or the consideration of the two remaining components.

\subsection{Incentive Mechanisms}

Starting from the situation that a customer initiates a request to a network for the production of a good, the network management has to search for suitable network participants. In some cases the situation can arise that not for every value-adding step a suitable enterprise could be found. Several reasons for that situation are imaginable. In case one or more core competences are not represented by network members, external partners need to be acquired. However in case every value-adding step could be realised by at least one enterprise there is a different situation. In that case the "missing" enterprises need to be convinced to participate. One reason can be the lacking profitability of an order.

Economic transaction is fulfilled by two actor groups: principals and agents. In network theory the network management can be interpreted as principal while the network participants (SME) act as agents. Both parties tend to maximise their utility with respect of their economic activities. In case an enterprise does not want to participate in a value-adding process although it has the necessary core competences the decision comes from the tendency for maximisation of utility. In that case incentives can be granted to convince the enterprise to participate. The incentive mechanism will be successful when the enterprise accepts the incentive. That process can be described as harmonisation of interests of principal and agent.

Based on that idea quantitatively orientated incentive mechanisms for the participation of enterprises in networks for the case core competencies are missing for one special value adding process can be applied. For example it can be imagined that the profit of the entire network can be increased in case one specified enterprise can be engaged which under regular conditions would not take part. Therefore it is necessary to grant incentives. In that case monetary incentives seem to be most efficient. 


\subsection{Sanction Mechanisms}

According on the realised performances of an SME, sanction mechanisms represent a further valuable instrument of the network controlling. This mechanism is applied in case the performance agreed upon has not been completed in a satisfying degree considering selected performance indicators. Sanctions reduce the individual profit share and need to be restricted to an extension that is recognised as justified by the enterprises involved.

Sanctions must not lead to the fact that a future cooperation is made harder or does not even take place. For the quantification of sanctions the observation of the behaviour of the enterprises with regard to the fulfilment of the contract is necessary in order to quantify the sanction amount [3]. Within that scope, the actual and target values of important performance attributes are balanced for every enterprise participating at a value-adding process. A "degree of fulfilment" in the sense of a credit evaluation needs to be determined for each of those parameters. The ascertained degree of fulfilment as an actual value is subsequently compared to the target value for every attribute.

The variable "network conformity" is finally ascertained by the means of a weighting of the single parameters. This aggregated variable is considered after finishing the value-adding process in the profit division model. Therefore, a connection is made between the "network conformity" and the payment of enterprise-specific profit shares by means of a function.

\section{Approaches for Profit Division}

\subsection{Conceptual Framework}

All subsequently introduced approaches for profit division consider three influence parameters. There are a value-adding-independent (fixed), a value-adding-dependent (variable) part and a profit expectation-dependent component. The profit share of an enterprise which is determined by the last mentioned influence factor is called profitexpectation-dependent profit share. The individual profit expectation of an enterprise (with regard to the individual value-adding-share) can be indicated as an amount or a percentage of the value-adding-share. It is stored in a central data base which is neither accessible to the network members nor to the broker instance. There is no "open book" strategy within the cooperation.

In the further modelling it has to be differentiated whether the product offer price of the network (respectively the offer profit) correspond to the final sales price (respectively the sales profit) to the customer. Thus, several possibilities of component integration arise for the calculation of the profit shares. The following sections will focus that structure. A further approach consists in the introduction of weightings for each component which is not discussed in this contribution.

In principle, the calculation of the network profit calculated in the offer is based on the individual profit expectations of the enterprises. However, it is imaginable 
that, after the value adding-process has been finished, the divided profit expectationdependent profit share does not correspond to the complete profit that can be divided among the network members. This so-called undivided remaining profit is negative if a too high amount has been divided already whereas it is positive if a profit share remains and can be divided. In both cases, measures need to be taken in order to exactly divide the earned profit. Therefore, either a corresponding revaluation or devaluation by the help of a standardisation parameter or the consideration of the two remaining components are imaginable. While the first mentioned approach will be discussed in section 3.2.1, the second option will be focussed in section 3.2.2. For the less complicating case that the offer profit and the realised profit correspond to each other, two different approaches are discussed next in the sections 3.3.1 and 3.3.2.

It has to be stressed that the different approaches for profit division presupposes a flat-hierarchical structure of the cooperation with an independent broker unit. The sensible data are stored centrally for the calculation of individual profit shares in an automated way using the modern information and communication technology.

\subsection{Models considering no remaining profit}

\subsubsection{Enterprise-related profit expectation as a basis}

The calculation of the offer is based on the individual value-adding-shares of the cooperation members and the corresponding profit expectations an enterprise stated. If the offer including the suggested price is accepted by a customer, the goods are produced and delivered. Usually, the customer then pays the agreed sales price including the profit, which is based on the individual profit expectations and thus corresponds to the offer price. The achieved profit can be completely divided to the participating enterprises of the network. No amount remains undivided. The calculation of the enterprise-related profit shares results from multiplying the enterprise-related profit expectation (in per cent) by the net value-adding of an enterprise.

Basically, enterprises are given their desired profit share without any reductions or supplements. The divided (profit-expectation-dependent) profit results from the sum of individual profit expectation-dependent profit shares of all enterprises. This profit expectation-dependently divided profit corresponds to the offer profit and thus, the complete profit was divided. There is no remaining profit. One problem of this procedure is the initial parameter "individual profit expectation". The enterprises indicate this parameter independent from a certain value adding-process. However, there is the problem of intended incorrect information. For this reason, a parameter should be introduced which eliminates outliers and obviously wrong numbers. This parameter is called the average percentage of the expected profit and it is equal for all enterprises. However, that the divided profit does not necessarily correspond to the profit that can be divided. Thus, further mechanisms need to be applied which are also valid if a profit, that can be divided, was achieved which deviates from the offer profit. These mechanisms are considered in the following section. 


\subsubsection{Enterprise-related average profit expectations as a basis}

For calculating the (weighted) average profit (measured in per cent of the valueadding share), the individual percentage of the profit expectation is weighted by the share of the individual value-adding-process of the complete value-adding-process. Thereby, it has to be considered that this parameter is enterprise-independent. In the next step, it is possible to ascertain the profit expectation-dependent profit share for every enterprise. This variable represents the most important component of the complete profit share of an enterprise. Finally, the complete (profit expectationdependent) profit, that has so far been paid out, results from the sum of those individual profit expectation-dependent profit shares of all enterprises. Summing up the profit shares per enterprise is necessary in order to determine the further procedure. Thus, a comparison between the already divided profit and the profit after the value adding-process, that can in total be divided, is the next step. By subtracting the already divided profit from the distributable profit, a non-divided remaining profit results, which still can be divided among the enterprises

The total profit could be completely divided based on the (non-weighted) profit expectation (per cent). When applying the profit expectation, that is weighted using the individual value adding-process, it has to be checked subsequently if this condition is fulfilled. Here, it is significant to stress an effect of the application which occurs in case the offer profit corresponds to the distributable profit. Starting from the enterprise-related percentage of the profit expectations (related to the enterprise-related net value-adding-process and unweighted), the profit expectationdependent profit share is calculated by multiplication. This procedure usually leads to different values. It can be remarked that the distributable profit $\mathrm{G}$ will in any case need to be divided among the enterprises without a remaining profit. This happens independently from the kind of calculation. This effect is especially interesting because thus it is made sure that this procedure provides usable results in a simple way despite of the improved modelling. It is guaranteed that this approach does not provide any procedure-specific remaining profit. However, those procedure-specific remaining profits must not be changed with the remaining profits, which occur in case the distributable profit from the sales price is higher than the offer profit in the offer price. This will be the focus of the following sections.

\subsection{Models considering a remaining profit}

\subsubsection{Solution with a standardisation parameter}

In case the distributable profit differs from the offer profit the balance is called remaining profit. That amount can be positive (realised profit $>$ offer profit) or negative (realised profit $<$ offer profit). In both cases, a corresponding division mechanism needs to be applied for the remaining profit. One possibility is the application of a standardisation parameter.

In the following, that procedure will be described. It is assumed that a partial amount of the realised profit could be divided based on individual profit expectations. Hereby it is of secondary importance whether the division took place based on the individual profit expectation or on the weighted profit expectation, 
because of the same character. In case a profit could be realised which exceeds the divided profit an alternative division approach is required. The suggested standardisation parameter is calculated by proportioning the total profit and the profit expectation-dependent profit share that has already been divided. Finally, the profit that has already been divided depended on the expectations of the enterprises is multiplied with the standardisation parameter for calculating the individual profit share of an enterprise. When calculating using concrete figures, it strikes that the profit share of an enterprise of the complete profit corresponds to the value addingshare of an enterprise of the entire value adding-process.

\subsubsection{Division by means of a fixed and a variable profit share}

A further division variant results by the inclusion of fixed and variable profit shares in addition to the profit expectation-dependent profit share. This approach can again be applied for positive as well as negative remaining profits. The division of that remaining non-divided profit is made subsequently by a fixed and a variable profit share. The undivided remaining profit hereby is divided by the number of active enterprises of the network and multiplied by a parameter which weights the fixed share. The remaining variable profit share is calculated by multiplying the corresponding weighting parameter with the undivided remaining profit and the ration of the individual value adding share to the total value adding of the network. The sum of both weighting parameters must be one.

By applying those interdependencies, a division of the profit to the enterprises that is based on three components is realised. The calculation of the complete profit share of an enterprise results by summing up the profit expectation-dependent profit share, the fixed profit share and the variable profit share.

It becomes clear that this model applies a division parameter. Several possibilities are imaginable for determining that parameter [3]. Thereby, it seems to be probable that, after the division, the complete profit still has not been divided. In that case the standardisation parameter must be applied again.

Because on the one hand, the performance-oriented profit division is favoured, but on the other hand enterprise with a small value-adding share should not be disfavoured, the profit division based on three components and using a variable division parameter is recommended in case the numbers are similar.

\subsection{Findings}

The necessity of taking remaining profits into consideration predominantly arises when the offer price and the sales price (and thus offer profit and sales profit) do not correspond. It has to be remarked that the application of weighting parameter is only obligatory in selected situations. In principle, several weighting parameters could be applied in this connection. Our example, however, is restricted to the application of an individualised division parameter. All the further models render that parameter dispensable - a fact that is absolutely desirable because the (only) consideration of the enterprise-related profit expectation promises a higher rate of being accepted by end-consumers. However this option will increase the complexity of the process. 


\section{Conclusion}

Selected approaches for the division of profit were introduced in this paper. These methods serve different functions. In order to give a wider comprehension also incentive and sanction mechanisms as well as the fundamental framework were introduced. Transferring the approaches into practice seems efficient and disposes of a high success potential with regard to the structure and operation of promising cooperations. Thereby, it especially has to be stressed that the introduced approaches for the profit division within networked production structures have predominantly been formulated quantitatively and therefore meet the claim of having a high level of automation. The individual maximisation of utility can be considered as well by including an expectation-dependent component. It has to be mentioned that the introduced profit division approaches presuppose a high degree of automation of the network controlling processes. That precondition is fulfilled by the network operation and coordination concept Extended Value Chain Management (EVCM) in an outstanding way. Furthermore all network participants must agree the application of a suitable model. In practice the high degree of automation can lead to a shorter time from request to offer and a shorter process time. Within that framework the application of the EVCM including the profit division approach can serve as a valuable instrument of network controlling helping especially SME to cope with the challenge of global competition and rising process costs.

\section{Literature}

1. T. Teich, Extended Value Chain Management (EVCM) - Ein Konzept zur Koordination von Wertschöpfungsnetzen (Verlag der GUC, Chemnitz, 2003).

2. E.G. Furubotn, R. Richter, Institutions and Economic Theory: The Contribution of the New Institutional Economics, 2nd ed., (University of Michigan Press, Ann Arbor, 2005).

3. H. Jähn, M. Fischer, M. Zimmermann, An Approach for the Ascertainment of Profit Shares for Network Participants, in: Collaborative Networks and their breeding Environments, edited by L.M. Camarinha-Matos et al. (Springer, New York, 2005, pp. 257-264.

4. B. Fromen, Faire Aufteilung in Unternehmensnetzwerken (DUV, Wiesbaden, 2004).

5. E. Sucky, Koordination in Supply Chains (DUV, Wiesbaden, 2004).

6. H. Rehkugler, Die Verteilung einzelwirtschaftlicher Wertschöpfung (Disertation, Ludwig-Maximilians-Universität, München, 1972).

7. M.A. Krajewska, H. Kopfer, Profit Sharing approaches for freight forwarder: An overview, in: Logistics, Supply Chain Management and Information Technologies, edited by. D. Ivanov, A. Kuhn, V. Lukinskiy (Saint Petersburg Publishing House of the State Polytechnic University, St. Petersburg, 2006).

8. M. Jin, S.D: Wu, Supplier coalitions in on-line reverse auctions: Validity requirements and profit distribution scheme, International Journal of Production Economics 100, 183-194, (2006). 